https://doi.org/10.30910/turkjans.448383

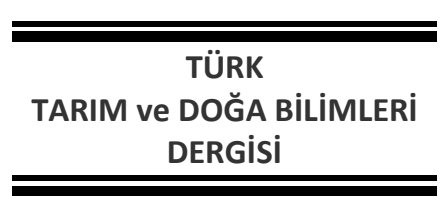

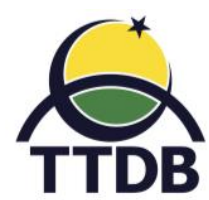

www.dergipark.gov.tr/turkjans

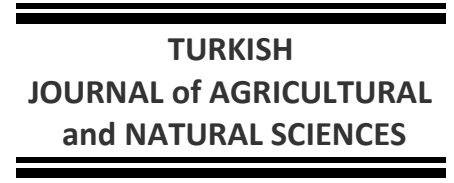

Araştırma Makalesi

\title{
Bazı Amerikan Anaçlarının Kabarcık ve Hönüsü (Mahrabaşı) Üzüm Çeşitlerinde Aşı Başarısı ve Fidan Kalitesi Üzerine Etkileri
}

\author{
Muhammet Ali GÜNDEŞLi*
}

Doğu Akdeniz Geçit Kuşağı Tarımsal Araştırma Enstitüsü Müdürlüğü, Kahramanmaraş, TÜRKiYE

*Sorumlu yazar: maligun46@hotmail.com

Geliş Tarihi: 23.01.2018_ Düzeltme Geliş Tarihi: 11.07.2018_Kabul Tarihi: 16.07.2018

\section{Özet}

Bu araştırma fidanlık şartlarında Kabarcık ve Hönüsü (Mahrabaşı) üzüm çeşitlerinin 1103 Poulsen ve 110 Richter Amerikan asma anaçları üzerine aşılı fidanlarda; fidan randıman ve kalitesine üzerine etkilerini belirlemek amacıyla 2016-2017 yıllarında yürütülmüştür. Araştırmada Kabarcık ve Hönüsü üzüm çeşitleri, omega aşı yöntemi ile iki farklı anaç (1103 Poulsen ve 110 R) üzerine aşılanmıştır. Parafinlenen aşılı çelikler, su kültüründe 4 hafta süre ile iklim odasında $\left(23-25^{\circ} \mathrm{C}\right.$ ve \% 75-90 oransal nem) beklemeye alınmıştır. Aşı kesitinin \%75'ini saracak şekilde kallus oluşturan aşılı çelikler, bahçe toprağı, perlit, dere mili ve yanmış ahır gübresinden (1:1:0.5:0.5) oluşan harç ortamına dikilerek, 6 hafta kontrollü şartlarda $\left(25\right.$ ve $27^{\circ} \mathrm{C}, \% 70-75$ oransal nem ve 16 saat fotoperiyot) köklendirilmeye bırakılmıştır. Köklenen fidanlar dış şartlara aktarılarak gölgeleme evine alınmıştır.Araştırma sonucunda, aşı yerinde kaynaşma oranı (\%), kaynaşma düzeyi (0- 4), anaç kalınlığı (mm), aşı noktası kalınlığı (mm), sürme ve köklenme oranı (\%), kök sayısı (adet/fidan), kök uzunluğu (cm) ve fidanlığa dikilebilecek aşılı çelik oranı (\%) ile fidan kalitesi ve eldesi yönünden anaçların farklı etkilere sahip olduğu tespit edilmiştir. Fidan randımanı bakımından, en iyi sonuç Kabarcık/1103 Poulsen (\%60.66) elde edilmiş; en düşük fidan randımanı ise, \%37.00 ile Kabarcık/ 110-R'de belirlenmiştir. En yüksek köklenme oranı ise \%68.50 ile 1103 Poulsen anacında gerçekleşmiştir. Araştırmanın yürütüldüğü bölge şartlarında, üzüm çeşitlerinin gösterdiği en iyi fidan kalitesi 1103 Poulsen anacı üzerine aşılı çeşitlerde olduğu belirlenmiştir.

Anahtar kelimeler: Anaç, kabarcık, hönüsü (mahrabaşı), 1103 Poulsen, 110-R, Kahramanmaraş.

\section{The Effects of Some American Rootstocks on Grafting Success and the Quality of Grafted- Vine in Kabarcik and Hönüsü Grapevine Cultivars}

\begin{abstract}
This research was carried out under nursery conditions, in 2016-2017 with the aim of determining the take the ratio of grafted vines and quality of grapevine saplings of Kabarcık and Hönüsü varieties grafted on American rootstocks (1103 Poulsen and 110-R). Grapevine 'cv. 'Kabarcık' and 'Hönüsü' was grafted on two different rootstocks by omega grafting method. Paraffined grafted cuttings were stratified in kept in a water bath and then placed into climate room $\left(23-25^{\circ} \mathrm{C}\right.$ and $75-80 \%$ relative humidity) for 4 weeks. Grafted cuttings, having $75 \%$ callusing on graft union were planted in garden land, perlite, stream shaft and burnt farmyard manure (1:1:0.5:0.5) mixture and rooted under controlled conditions $\left(25\right.$ and $27{ }^{\circ} \mathrm{C}, \% 70-75$ relative humidity and $16 \mathrm{~h}$ photoperiod) for six weeks. The rooted seedlings were transferred to the shading house by transferring them to external conditions. As a result of this study, the rootstocks had different effects in terms of callusing, rooting and sprouting ratios (\%), callusing levels (0-4), rootstock thickness $(\mathrm{cm})$, vaccination point thickness (mm) number of roots, root length $(\mathrm{cm})$ the ratio of grafted cuttings having planting quality (\%) and the ratio of grafted vines (\%). Regarding the ratio of grafted vines, the best results were obtained from Kabarcık/1103 Poulsen (60.66\%), the lowest ratio was determined in $110-\mathrm{R}$ with $37.00 \%$. The highest rooting rate was achieved in 1103 Poulsen rootstock with $68.50 \%$. Under the conditions of the study area, the best variety quality of the grape varieties was determined to be in the grafted varieties on 1103 Poulsen rootstock. .
\end{abstract}

Key words: Rootstock, kabarcık, hönüsü (mahrabaşı), 1103 Poulsen, 110-R, Kahramanmaraş. 


\section{Giriş}

Modern meyvecilikte başarının ön şartı; bağ alanlarının ve meyve bahçelerinin, ismine doğru, hastalık ve zararlılar karşı dayanıklı sağlıklı ve kaliteli fidanlarla kurulmasıdır. Bu nedenle yeni bağ alanlarının kurulmasında en önemli aşamalarından biri anaç ve çeşit seçimidir (Söylemezoğlu ve ark., 2015). Bu bağ tesisinin uzun ömürlü ve ekonomik bir yatırım olmasının ön şartıdır. Bu seçimin, bölgenin ekolojik şartlarının göz önünde tutularak dikkatli yapılması önem arz etmektedir. Dünyada bağ yetiştiriciliği yapan ülkelerin çoğunda bağların tamamı sertifikalı ve hastalıklara dayanıklı fidanlar ile kurulmaktadır. Ancak ülkemizde bağ yetiştiriciliğinde, yöre üreticileri floksera ile bulaşık olmasına dikkat etmemekte, birçok yetiştirici aşısız Amerikan asma anaçları ile dikim yapmakta, bu anaçlar aşıya gelince istedikleri yerli çeşitleri bu anaçlar üzerine aşılama yapmaktadırlar. Bunun sonucunda üreticiler birçok sorun ile karşı karşıya gelmektedirler. Flokseranın hızla yayılması ile bağların hızla elden çıkmaya başlaması, gerek aşıcı ustasının bulunmaması, tesis maliyetinin yüksekliği ve verimde düşüklük, para ve zaman kaybına yol açmaktadır. Bu bölgelerde bulunan yetiştiriciler bağlarını yenilemek istemekte ve sağlıklı ve kaliteli aşılı asma fidanı ile bahçelerini kurmaya çalışmaktalar. Bu nedenle fidan talebinin hızla artış gösterdiği görülmektedir. Ancak yurdumuzda bu tip asma fidanlarının üretimi yeteri olmamakla beraber, fidan üretimine yeni başlanmakta ve gün geçtikçe fidan talebinde de artış olmaktadır (Çelik ve Odabası, 1994; 1995; Ecevit ve Baydar, 2000; Turkben ve Sivritepe, 2000; Göktaş, 2008; Çakır ve ark., 2013; Arslan, 2015; Sucu ve Yağcı, 2017).

Ülkemizde asma fidanı çoğunlukla Gıda, Tarım ve Hayvancılık Bakanlığı'na bağlı Araştırma Enstitüleri tarafından üretilmektedir. Ayrıca Ege ve Marmara gibi bağ yetiştiriciliğinde ve üretimde gelişmiş bölgelerim yanı sıra ve diğer bölgelerde de özel asma fidanı üreten firmalar da olduğu ama bu firmaların yeterli olmadığı görülmektedir. Ülkemizin bazı yörelerinde ise, bağcılar kendi ihtiyaçlarını karşılamak ve yerel çeşitleri korumak adına asma fidanı üretmektedirler. Ancak bu üretimin bazı bölgelerde modern olarak yapılmadığı ve bazı sorunlar ile karşı karşıya gelindiği görülmektedir (Çelik, 1985; Tangolar ve Ergeneoğlu, 1989; Çelik ve Odabaşı, 1995; Çelik ve ark., 1998; Türkben ve Sivritepe, 2000).

Çizelge 1'de görüldüğü gibi, Türkiye'de hem özel sektör, hem de kamu kuruluşlarınca fidan üretimi gerçekleştirmesine rağmen üretimin düşük olduğu görülmektedir. Ülkemizin 2012-2016 yıllarına ait toplam asma fidan üretimi yıldan yıla farklılıklar neticesinde, dalgalı bir değişim göstermektedir. Ülkemizde bağcılık sektörünün önemi dikkate alındığında bu üretimin yetersiz olduğu görülmektedir (Çizelge 1).

Çizelge 1. 2012-2016 yılları arası ait toplam sertifikalandırılan asma fidan miktarları (adet).

\begin{tabular}{cc}
\hline Yıllar & Asma \\
\hline 2012 & 3393588 \\
2013 & 7129690 \\
2014 & 5465230 \\
2015 & 4981436 \\
2016 & 4349560 \\
\hline
\end{tabular}

Kaynak: Anonim 2017

Bağ yetiştiriciliğinde kullanılan anaç ve üzüm çeşitlerinde farklı ekolojik koşullara uyumu ve uyuşmasında farklılıklar olmakta ve çeşit-anaç ilişkilerinde bitki büyüme ve gelişme, verim, kalite, affinite ve adaptasyon gibi problemler ile karşı karşıya gelmektedir. Bu nedenle, bağ yetiştiriciliğinde kullanılan anacın çeşitle iyi affinite göstermesi, yörenin ekolojik koşullarına uyum sağlaması, çeşidin fizyolojik büyüme periyodunda büyüme ve gelişme özellikleri üzerine etkilerinin belirlenmesi gerekmektedir (Çelik ve Odabaşı, 1994; 1995; Türkben ve Sivritepe, 2000; Çelik ve ark., 2010). Tersi durumda özellikle bağ alanlarının uzun ömürlü ve ekonomik olmamaktadır. Bu nedenle yeni kurulacak bağ alanlarının uzun ömürlü ve ekonomik olabilmesi için bölgeye uygun anaç ve çeşidin seçilmesi gerekmektedir.

Kahramanmaraş ilinde özellikle Bertiz yöresi, yoğun yetiştiriciliği yapılan Kabarcık ve Hönüsü üzüm çeşidinin kendine özgü tadı ile özel bir ekolojiye sahip olup, ender bağcılık potansiyeline sahip ilimizdir. Kahramanmaraş ili üretim alanı ve miktarı bakımından ülkemiz bağcılığında 274.280 da alanda 199.442 ton üretim ile önemli bir paya sahiptir (TÜiK, 2017). Bu üretimin çoğunluğu çekirdekli kuru üzüm üretimine yönelik olup özellikle Kabarcık üzüm çeşidi ilimiz önemli bir yere sahiptir. Uzun yıllardan beri daha çok engebeli ve küçük parçalı araziler üzerinde yerel Kabarcık ve Hönüsü çeşitleri ile süregelen yetiştiricilik, ova bölgesine kurulan modern bağ alanlarıyla gün geçtikçe artmaktadır. Ancak iklim ve toprak yapısı ile bağcılık açısından oldukça uygun olan ilimizde, doğru yetiştiricilik sistemlerinin ve ismini doğru setifikalı fidan kullanılmaması nedeniyle birim alana verimlilik oldukça düşük kalmaktadır. Bu nedenle, bölge üretimine katkı sağlayacak anaçların da bir an önce belirlenmesi elzemdir.

$\mathrm{Bu}$ amaçla bu araştırmada, Kahramanmaraş'ın bağcılık konusunda sorunlarının çözümüne katkı sağlamak amacıyla bölgede yoğun yetiştiriciliği yapılan Kabarcık ve Hönüsü üzüm çeşitlerinde tüplü aşılı asma fidanı üretiminde, farklı 
anaçların aşıda başarı üzerine etkileri araştırılmıştır. Araştırmada, Kabarcık ve Hönüsü üzüm çeşitlerinin bölge koşullara uyum sağlamasına yardımcı olabilecek çalışmalar ve yetiştiricilikte kullanılmış olmasına rağmen aşı özellikleri belirlenmemiş asma anaçları incelenmiştir.

\section{Materyal ve Yöntem Materyal}

Bu araştırma 2016 ve 2017 yıllarında, Kabarcık ve Hönüsü (Mahrabaşı) üzüm çeşitleri ile 1103 Paulsen ve 110 Richter Amerikan asma anaçlarına ait, 1.boy (TS 4027) çelikler kullanılarak yapılmıştır. 1103 Paulsen ve $110 \mathrm{R}$ asma anaçlarına ait, 1.boy (TS 4027) anaçlık çelikler Doğu Akdeniz Geçit Kuşağı Tarımsal Araştırma Enstitüsünden Kabarcık ve Hönüsü (Mahrabaşı) üzüm çeşitlerine ait kalemlik çelikler ise Kahramanmaraş Kabarcık üzüm çeşidin yoğun olarak yetiştirildiği Bertiz Köyü üretici bahçesinden elde edilmiştir.

\section{Yöntem}

Şubat ayı içerisinde alınan çelikler, önce Rovral Iprodine 50 WP (\%0.75) ile özellikle fungal etmenlere karşı muamele edilerek demetler (100 adet) halinde polietilen torbalara alınmıştır. $+4^{\circ} \mathrm{C}$ sıcaklık ve \%75-90 nem koşullarında soğuk hava deposunda aşı dönemine kadar muhafaza altına alınmıştır. Aşılamadan önce, çeliklerin alt kısımlarından $10 \mathrm{~cm}$ derinliğinde suya daldırılmış; $18^{\circ} \mathrm{C}$ ile $22^{\circ} \mathrm{C}^{\prime}$ de anaçlar 48 , kalemler 24 saat süre ile suda beklemeye alınmıştır (Laszlo ve Valeanu, 1969). Mart ayının ikinci haftasında omega $(\Omega)$ kesit aşı makinesi ile aşı işlemlerine başlanmıştır. Daha sonra aşılı çelikler, aşı yerinin saracak şekilde, 70 ve $80{ }^{\circ} \mathrm{C}^{\prime}$ de eriyebilen ticari parafin kullanılarak parafinlenme işlemi uygulanmıştır. Daha sonra çelikle plastik kasalar içerisinde kaynaştırma odasına yerleştirilmiş ve su içerisinde köklenme ortamına alınmıştır. Sıcaklığı $22-28^{\circ} \mathrm{C}^{\prime}$ de ve oransal nem \%75-85 arasında değişen iklim odasında alınmış ve belli aralıklarla havalandırma yapılmıştır. Yaklaşık 1 ay sonra iklim odasından alınan çeliklerde; aşı yerinde kaynaşma oranı (\%), kaynaşma düzeyi (0-4), anaç kalınlığı $(\mathrm{mm})$, aşı noktası kalınlığı (mm), ve köklenme oranı (\%), kök uzunluğu (cm), sürme oranı (\%) ve Fidan Randımanı (\%) belirlenmiştir (Çelik, 1982; Akman ve Ilgın, 1991; Altındişli ve ark., 1998).

Kaynaşma oranı, aşı kesitinin en az 1/4 'ünü saracak şekilde kallus oluşturan aşılı çelikler değerlendirmeye tabi tutulmuş, kaynaşma düzeyin Çelik (1982)'e göre belirlenmiştir. Aşı kesiti en az \%75 kallus oluşturan fidanların siyah polietilen torbalara alınmıştır. Torbalarda bahçe toprağı, perlit, dere mili ve yanmış ahır gübresi (1:1:0.5:0.5) olan harç yer almaktadır. Aşılanan çeliklerin 23 ve $25^{\circ} \mathrm{C}$ sıcaklık, $\% 75-85$ oransal nem ve 16 saat gün ışığına sahip kontrollü şartlarda, 6 hafta köklenmesi sağlanmıştır. 3. haftadan sonra ise sadece sürgünlerin temizleme işlemi uygulanmıştır. Aşılı tüplü fidanlar Haziran ayının ilk haftasında \%40 oranında gölgeleme sağlayan yeşil jüt örtü kullanılarak gölgeleme evine yerleştirilmiştir. Temmuz ayı ortasında sürgün gelişimi ve köklerin polietilen torbaların drenaj deliklerinden dışarı çıkma durumların göre, fidan randımanı (\%) belirlenmiştir (Laszlo ve Valeanu, 1969).

Araştırma tesadüf parselleri deneme deseninde, 3 tekerrürlü ve her tekerrürde 50 adet aşılı çelik yer alacak şekilde kurulmuştur. Araştırma sonuçları varyans analizleri 0.05 önemlilik seviyesinde ve uygun istatistik bilgisayar programı kullanılarak yapılmıştır. 0.05 önemlilik seviyesinde LSD testi ile değerlendirilmeye tabi tutulmuştur.

\section{Bulgular ve Tartışma}

$1103 \mathrm{P}$ ve $110 \mathrm{R}$ Amerikan asma anaçları üzerine aşılanmış Kabarcık ve Hönüsü üzüm çeşitlerindeki kaynaşma oranları Çizelge 2'de verilmiştir. Çizelge 2'de görüldüğü gibi Kabarcık ve Hönüsü çeşitlerinde kaynaşma oranları (\%) etkileri açısından anaç, çeşit/anaç arasında \%5 düzeyinde önemli bulunmuştur. Çeşitler arasında en yüksek değer Kabarcık üzüm çeşidinde (\%87.33) tespit edilmiş, anaçlar değerlendirildiğinde en yüksek değer 1103 Poulsen anacında (\%92.50) en düşük değeri ise 110-R (\%75.17) anacında tespit edilmiştir. Çizelge 2'de görüleceği gibi, 1103 Poulsen üzerine Kabarcık aşı kombinasyonunda kaynaşma oranlarının yüksek olmasının fidanlığa dikilebilecek nitelikte aşıı çelik oranlarını da etkilediği anlaşılmaktadır. Anaçların ve çeşitlerin kaynaşma oranları üzerine interaksiyonunun önemli derecede etkili olduğu belirlenmiştir.

Çeşit $X$ anaç interaksiyonu kaynaşma oranları acısından incelendiğinde, 1103 Poulsen/Kabarcık kombinasyonu en yüksek değere (\%95.00) ulaşmış, 110-R/ Hönüsü üzüm çeşidinde ise en düşük değer (\%70.67) saptanmıştır (Çizelge 2).

Bağ yetiştiriciliğinde yapılan aşıların başarının ön koşulu olarak anaç ile kalem arasında iyi bir affinite bulunması gerekir, anaç ile kalem arasındaki akrabalık aşıdaki başarı şansını da arttırmaktadır (Hartman ve Kester, 1974). Çelik ve Ağaoğlu (1979), 5 BB anacı üzerine aşılanan Hasandede, Hamburg Misketi ve Emir üzüm çeşitlerinde kallus oluşumunun \%92 ile \%100 arasında olduğunu belirtmişlerdir. Sivritepe ve Türkben (2001), 41 B ve 1616 anacı üzerine aşılanan Müşküle çeşidinde yaptıkları çalışmada, kaynaşma oranının \%80-97 olduğunu, farklı çeşitlerin ve farklı yetiştirme ortamlarına göre aşı başarısının değiştiğini bildirmişlerdir. 
Çizelge 2. Farklı anaçların kabarcık ve hönüsü (mahrabaşı) üzüm çeşitlerinin kaynaşma oranları (\%).

\begin{tabular}{|c|c|c|c|}
\hline \multirow[t]{2}{*}{ Anaçlar } & \multicolumn{2}{|c|}{ Çeşitler } & \multirow[t]{2}{*}{ Anaç ortalama } \\
\hline & Kabarcık & Hönüsü (Mahrabaşı) & \\
\hline 1103 Poulsen & $95.00^{\mathrm{a}}$ & $90.00^{b}$ & $92.50 \mathrm{~A}$ \\
\hline $110-\mathrm{R}$ & $79.66^{c}$ & $70.67^{d}$ & 75.17B \\
\hline Çeşit ort. & $87.33 \mathrm{~A}$ & $80.33 B$ & \\
\hline D Anaç $: 2.44^{* *}$ & & $: 2.46^{* *}$ & D Anaç x Çeşit : $3.48^{*}$ \\
\hline
\end{tabular}

(1): Ortalamalar arasındaki farklar farklı harflendirilmeyle belirtilmiştir.

(2): Ö.D.: Önemli Değil, **:p<0.01; * $: p<0.05$

Çizelge 3 incelendiğinde ortalama kaynaşma düzeyleri (0-4) etkileri açısından anaç, çeşit/anaç arasında \%5 düzeyinde önemli bulunmuştur. Çeşitler bakımında en yüksek miktar Kabarcık üzüm çeşidinde (3.18) tespit edilmiştir. Anaçlar yönünden incelendiğinde en yüksek miktarı 1103 Poulsen anacında (2.88) en düşük değeri ise
110-R (2.60) aşı kombinasyonlarında tespit edilmiştir. Çeşit/anaç arasında kallus oluşturma acısından değerlendirildiğinde, 1103 Poulsen/Kabarcık üzüm çeşidi en yüksek miktara (3.26) ulaşırken, en düşük değer (2.10) Hönüsü üzüm çeşidinde saptanmıştır (Çizelge 3 ).

Çizelge 3. Farklı anaçların kabarcık ve hönüsü (mahrabaşı) üzüm çeşitlerinin kaynaşma düzeyleri (0-4).

\begin{tabular}{|c|c|c|c|}
\hline \multirow[t]{2}{*}{ Anaçlar } & \multicolumn{2}{|c|}{ Çeşitler } & \multirow[t]{2}{*}{ Anaç ortalama } \\
\hline & Kabarcık & Hönüsü (Mahrabaşı) & \\
\hline 1103 Poulsen & $3.26^{a}$ & $2.50^{\mathrm{b}}$ & $2.88 \mathrm{~A}$ \\
\hline $110-R$ & $3.10^{b}$ & $2.10^{c}$ & $2.60 \mathrm{~B}$ \\
\hline Çeşit ort. & $3.18 \mathrm{~A}$ & $2.30 \mathrm{~B}$ & \\
\hline D Anaç: $0.25^{* *}$ & & $: 0.26^{* *}$ & D Anaç x Çeşit : $0.36^{*}$ \\
\hline
\end{tabular}

(1): Ortalamalar arasındaki farklar farklı harflendirilmeyle belirtilmiştir.

(2): Ö.D.: Önemli Değil, **:p<0.01; * :p<0.05. *Kallus oluşum değerleri; 0-4 skalası, 0: hiç kallus yok, 4: çepeçevre tam kallus

Anaçların ve çeşitlerin kaynaşma düzeyleri üzerine interaksiyonu önemli olduğu görülmektedir. Sivritepe ve Türkben (2001) 41 B üzerine aşılı Müşküle üzüm çeşidinde kaynaşma düzeylerinin (34) olduğunu, çeşitlere göre farklılıklar olduğunu belirtmişlerdir. Bu bulgular Çelik ve Akgül (1992), (2.75-3.30), ve Çoban ve Kara (2003)'nın (3.053.55) yaptığı çalışmadaki bulgularla büyük ölçüde örtüşmektedir.

Çizelge 4'e göre ortalama anaç kalınlığını anaç, çeşit/anaç arasında \%5 seviyesinde önemli bulunmuştur. Araştırma sonucunda, çeşitler arasında en yüksek değer Kabarcık üzüm çeşidinde (8.56 mm) tespit edilmiş, anaçlar yönünden ise en yüksek değer 1103 Poulsen anacında $(8.73 \mathrm{~mm}$ ) en düşük değeri ise $110-R(7.40 \mathrm{~mm})$ anacında tespit edilmiştir. Çeşit $x$ anaç interaksiyonunda anaç kalınlığı bakımından, 1103 Poulsen /Kabarcık üzüm çeşidi en yüksek değere $(9.33 \mathrm{~mm})$ ulaşırken, 110R/Hönüsü üzüm çeşidinde ise en düşük değer (7.00 $\mathrm{mm}$ ) saptanmıştır (Çizelge 4). Buna göre anaçların ve çeşitlerin anaç kalınlığının interaksiyonu önemli olduğu görülmektedir. Tunçel ve Dardeniz (2013) Razakı/5BB ve Victoria/5BB aşı kombinasyonlarında anaç kalınlıklarının ( 9.20 ve $9.21 \mathrm{~mm}$ ) olduklarını belirlemiş. Bu bulgular ile çalışmadaki bulgular arasında bazı farklılıklar olduğu bu farklılıkların kullanılan anaç ve çeşitlerden kaynaklandığı düşünülmektedir.

Aşı noktası kalınlığı ( $\mathrm{mm})$ bakımından çeşit/anaç kombinasyonları \%5 seviyesinde önemli farklılık tespit edilmiştir. Çeşitler bakımından değerlendirildiğinde, en yüksek değer Kabarcık üzüm çeşidinde (18.25 mm) saptanmış, anaçlar bakımından ise en yüksek değer 1103 Poulsen anacında $(17.93 \mathrm{~mm})$ en düşük değeri ise $110-\mathrm{R}$ (16.13) anacından tespit edilmiştir (Çizelge 5). Çeşit $X$ anac interaksiyonu aşı noktası kalınlığı bakımından değerlendirildiğinde, 1103 Poulsen/Kabarcık üzüm çeşidi en yüksek değere (18,53 mm) ulaşırken, 110$\mathrm{R} /$ Hönüsü üzüm çeşidinin ise en düşük değer $(14,30$ $\mathrm{mm}$ ) aldığı tespit edilmiştir (Çizelge 5). Buna göre anaçların ve çeşitlerin aşı noktası kalınlığının interaksiyonunun önemli olduğu görülmektedir. Tunçel ve Dardeniz (2013) Razakı/5BB ve Victoria/5BB aşı kombinasyonlarında aşı noktası kalınlıklarının (16.30 ve $17.80 \mathrm{~mm}$ ) olduklarını belirlemiş. $\mathrm{Bu}$ bulguların çalışmada bulgularla uyumlu olduğu görülmektedir. 
Çizelge 4. Farklı anaçların kabarcık ve hönüsü (mahrabaşı) üzüm çeşitlerinin anaç kalınlığı (mm).

\begin{tabular}{|c|c|c|c|}
\hline \multirow[t]{2}{*}{ Anaçlar } & \multicolumn{2}{|c|}{ Çeşitler } & \multirow[t]{2}{*}{ Anaç ortalama } \\
\hline & Kabarcık & Hönüsü (Mahrabaşı) & \\
\hline 1103 Poulsen & $9.33^{a}$ & $8.13^{b}$ & $8.73 \mathrm{~A}$ \\
\hline $110-R$ & $7.80^{\mathrm{b}}$ & $7.00^{c}$ & $7.40 \mathrm{~B}$ \\
\hline Çeşit ort. & $8.56 \mathrm{~A}$ & $7.56 \mathrm{~B}$ & \\
\hline D Anaç $: 0.50^{* *}$ & & $: 0.51^{* *}$ & D Anaç x Çeşit : $0.71^{*}$ \\
\hline
\end{tabular}

(1): Ortalamalar arasındaki farklar farklı harflendirilmeyle belirtilmiştir.

(2): Ö.D.: Önemli Değil, **:p<0.01; * $: p<0.05$

Çizelge 5. Farklı anaçların kabarcık ve hönüsü (mahrabaşı) üzüm çeşitlerinin aşı noktası kalınlığı (mm).

\begin{tabular}{|c|c|c|c|}
\hline \multirow[t]{2}{*}{ Anaçlar } & \multicolumn{2}{|c|}{ Çeşitler } & \multirow[t]{2}{*}{ Anaç ortalama } \\
\hline & Kabarcık & Hönüsü (Mahrabaşı) & \\
\hline 1103 Poulsen & $18.53^{\mathrm{a}}$ & $17.33^{b}$ & $17.93 \mathrm{~A}$ \\
\hline $110-\mathrm{R}$ & $17.96^{\mathrm{ab}}$ & $14.30^{c}$ & 16.13B \\
\hline Çeşit ort. & $18.25 \mathrm{~A}$ & $15.81 \mathrm{~B}$ & \\
\hline D Anaç: $0.81^{* *}$ & & $t: 0.83^{* *}$ & D Anaç x Çeşit : $1.15^{* *}$ \\
\hline
\end{tabular}

(1): Ortalamalar arasındaki farklar farklı harflendirilmeyle belirtilmiştir.

(2): Ö.D.: Önemli Değil, **:p<0.01; * : $<<0.05$

Çizelge 6'ya göre, kök Sayısı (adet) bakımından anaçlarda \%5 seviyesinde önemli farklılık tespit edilmesine rağmen çeşidin önemsiz olduğu belirlenmiştir. Anaçlar arasında değerlendirmede ise, 1103 Poulsen Amerikan asma anacı ortalama kök sayısı 12.33 adet/fidan ile en yüksek değeri sahip anaç olmuştur.

Çeşitler bakımından incelendiğinde, Kabarcık üzüm çeşidi (15.66 adet/fidan) en yüksek ortalama kök sayısına sahipken, Hönüsü çeşidinin kök sayısının 17.4 adet/fidan olduğu tespit edilmiştir. Çeşit/anaç interaksiyonu kök sayısı değerlendirildiğinde, Kabarcık/1103 Paulsen (15,66 adet/fidan), Hönüsü/1103 Paulsen (12.33 adet/fidan); kombinasyonlarının en yüksek kök sayısına sahip kombinasyonlar olduğu belirlenmiştir (Çizelge 6).

Çizelge 6. Değişik anaçların kabarcık ve hönüsü (mahrabaşı) üzüm çeşitlerinin kök sayısı (adet/fidan).

\begin{tabular}{|c|c|c|c|}
\hline \multirow[t]{2}{*}{ Anaçlar } & \multicolumn{2}{|c|}{ Çeşitler } & \multirow[t]{2}{*}{ Anaç ortalama } \\
\hline & Kabarcık & Hönüsü (Mahrabaşı) & \\
\hline 1103 Poulsen & $15.66^{\mathrm{a}}$ & $12.33^{\mathrm{ab}}$ & $14.00 \mathrm{~A}$ \\
\hline $110-\mathrm{R}$ & $9.00^{b}$ & $9.15^{b}$ & 9.07B \\
\hline Çeşit ort. & 12.33 & 10.67 & \\
\hline D Anaç: $2.85^{* *}$ & & : 2.86 Ö.D & D Anaç x Çeşit : 4.07 Ö.D \\
\hline
\end{tabular}

(1): Ortalamalar arasındaki farklar farklı harflendirilmeyle belirtilmiştir.

(2): Ö.D.: Önemli Değil, **:p<0.01; * : $<<0.05$

Anaçlar bakımından incelendiğinde, en yüksek değer 1103 Paulsen anacında (14.00 adet/fidan) en düşük değer ise 110R (9.00 adet/fidan) anacında tespit edilmiştir. Kök sayısında meydana gelen değişimde anaç özelliklerinin önemli olduğu görülmektedir (Şekil 5). Önceki yıllarda birçok araştırıcının tespit ettiği sonuçlar ile bu araştırma sonuçlarının benzerlik gösterdiği ancak bazı araştırmalarda farklılıklar olduğu, bu farklılıkların ise kullanılan çeşit ve ekolojik faktörlerden kaynaklandığı tespit edilmiştir (Çelik ve
Ağaoğlu, 1979; Cangi, 1998; Türkben ve Sivritepe 2000; Sivritepe ve Türkben 2001).

Çizelge 7'ye göre, köklenme oranı (\%) bakımından çeşit ve çeşit/anaç arasında istatistiki olarak önemli farkılık olmadığı ancak Anaç'ın etkisinde \%5 düzeyinde farklılıklar olduğu ortaya çıkmıştır. En yüksek köklenme oranı \%68.50 ile 1103 Paulsen anacında gerçekleşirken, 110R'de köklenme oranının \%56.33 olduğu belirlenmiştir. Özellikle 1103 Poulsen Kabarcık kombinasyonun köklenme oranının yüksek olduğu ve uyumlu olduğu belirlenmiştir (Çizelge 7). 
Çizelge 7. Değişik Anaçların Kabarcık ve Hönüsü (Mahrabaşı) Üzüm Çeşitlerinin Köklenme Oranı (\%)

\begin{tabular}{cccc}
\hline Anaçlar & \multicolumn{2}{c}{ Çeşitler } & Anaç ortalama \\
\hline 1103 Poulsen & Kabarcık & Hönüsü (Mahrabaşı) & \\
$110-R$ & $73.33^{\mathrm{a}}$ & $63.66^{\mathrm{b}}$ & $68.50 \mathrm{~A}$ \\
\hline Çeşit ort. & $61.00^{\mathrm{b}}$ & $51.67^{\mathrm{c}}$ & $56.33 \mathrm{~B}$ \\
\hline D Anaç: $3.87^{* *}$ & $67.16 \mathrm{~A}$ & $57.66 \mathrm{~B}$ & \\
\hline
\end{tabular}

(1): Ortalamalar arasındaki farklar farklı harflendirilmeyle belirtilmiştir.

(2): Ö.D.: Önemli Değil, **:p<0.01; * $: p<0.05$

Önceki yıllarda yapılan çalışmalar incelendiğinde, Eriş ve ark. (1989) 5 BB üzerine aşılı Hamburg Misketi ve Hafızali çeşitlerinde köklenme oranları sırası ile \%93 ve \%100 arasında olduğunu, Türkben ve Sivritepe (2000) de 1613 anacı üzerine aşılı Müşküle üzüm çeşidin de ise köklenme oranının \%45-60, kök sayısının ise 15-16 adet/fidan olduğunu saptamışlardır. Ağaoğlu ve Çelik (1978) ise 5 BB üzerine aşılı / Emir, Hasandede ve Hamburg Misketi çeşitlerinde \%52 ile \%92 arasında köklenme oranına sahip olduğunu bildirmişlerdir. Bulgularımızda; önceki araştırma sonuçlarıyla bazı farklılıklar olduğu görülmektedir. Bu farklılıklar kullanılan anaç ve çeşitlerin farklılığı ve farklı ekolojik koşullardan kaynaklandığı düşünülmektedir.

Çizelge 8'de görüleceği gibi, kök uzunluğu bakımından anaç, çeşit ve çeşit/anaç arasında \%5 düzeyinde önemli farklılıklar olduğu tespit edilmiştir. Çeşitler bakımından değerlendirildiğinde, en yüksek değer Kabarcık üzüm çeşidinde (11.35 $\mathrm{cm}$ ) saptanırken, anaçlar içerisinden en yüksek değer 1103 Poulsen anacında $(12.75 \mathrm{~mm}$ ) en düşük değeri ise $110-R(5.38 \mathrm{~cm})$ anacından tespit edilmiştir.

Çizelge 8. Değişik anaçların kabarcık ve hönüsü (mahrabaşı) üzüm çeşitlerinin kök uzunluğu (cm).

\begin{tabular}{|c|c|c|c|}
\hline \multirow[t]{2}{*}{ Anaçlar } & \multicolumn{2}{|c|}{ Çeşitler } & \multirow[t]{2}{*}{ Anaç ortalama } \\
\hline & Kabarcık & Hönüsü (Mahrabaşı) & \\
\hline 1103 Poulsen & $16.87^{\mathrm{a}}$ & $8.63^{b}$ & $12.75 \mathrm{~A}$ \\
\hline $110-R$ & $5.83^{c}$ & $4.93^{c}$ & $5.38 \mathrm{~B}$ \\
\hline Çeşit ort. & $11.35 \mathrm{~A}$ & $6.78 \mathrm{~B}$ & \\
\hline D Anaç: $1.75^{* *}$ & & it $: 1.76^{* *}$ & D Anaç x Çeşit : $2.51^{* *}$ \\
\hline
\end{tabular}

(1): Ortalamalar arasındaki farklar farklı harflendirilmeyle belirtilmiştir.

(2): Ö.D.: Önemli Değil, ${ }^{* *}: p<0.01 ;^{*}: p<0.05$

Sürme oranı (\%) bakımından anaç ve çeşit uguamalarında \%5 seviyesinde önemli farklılık tespit edilmesine rağmen çeşit/anaç kombinasyonunun önemsiz olduğu belirlenmiştir (Çizelge 10). Kaynaşma sırasında anaç ve çeşitlerin tümünde sürme meydana geldiği ve en yüksek sürme oranlarının, \%85.66 ile Paulsen anacına aşılı Kabarcık üzüm çeşidinde, \%80.50 ile 1103 Poulsen anacında, en düşük değeri ise Hönüsü üzüm çeşidinde \% 57.50 ile 110-R anacında olduğu belirlenmiştir (Çizelge 9).

Kamiloğlu ve Tangolar (1995), 41 B anacı üzerine aşılanan King's Ruby üzüm çeşidinin $\% 87$ sürme oranına sahip olurken, bunu $\% 60$ ile 5 BB anacının takip ettiğini belirlemişlerdir. Sivritepe ve Türkben (2001), 41 B üzerine aşılı Müşküle üzüm çeşidinde \%88.89 sürme olduğunu belirtirken 5BB/Müşküle kombinasyonunda $\% 47.78$ sürme meydana geldiğini belirlemişlerdir. Bulgularımızın; önceki araştırma sonuçlarıyla uyumlu olduğu ancak bazı farklılıkların olduğu görülmektedir. Bu farklılıklar kullanılan anaç ve çeşitlerin farklılığı ve farklı ekolojik koşullardan kaynaklandığı düşünülmektedir (Çizelge 9).

Çizelge 10'da, toplam fidan randıman incelendiğinde (çeşit, anaç ve çeşit $x$ anaç interaksiyonu) \%5 düzeyinde önemli bulunmuştur. Çeşitler bakımından değerlendirildiğinde en yüksek değer Kabarcık üzüm çeşidinde (\% 48.33), Çeşit/anaç kombinasyonlarında ise en yüksek değeri Kabarcık/1103 Poulsen (\%60.66), en düşük değer ise 37.00 ile 110-R / Kabarcık aşı kombinasyonlarından elde edilmiştir (Çizelge 10). Sivritepe ve Türkben (2001), 1616 ve 1613 anacı üzerine aşılı Müşküle üzüm çeşidinde \%65-75 arasında fidan randımanı olduğunu belirlemiştir. Cangi ve ark. (1999), 5BB üzerine aşılı 9 üzüm çeşidinde fidan randımanının \%37 ile \%57 oranlarında olduğunu ve köklenme ortamının fidan randımanı etkisi olduğunu belirmiştir. Araştırmadan elde edilen bulguların, önceki araştırma sonuçlarıyla uyumlu olduğu görülmektedir. 
Çizelge 9. Değişik anaçların kabarcık ve hönüsü (mahrabaşı) üzüm çeşitlerinin sürme oranı (\%).

\begin{tabular}{|c|c|c|c|}
\hline \multirow[t]{2}{*}{ Anaçlar } & \multicolumn{2}{|c|}{ Çeşitler } & \multirow[t]{2}{*}{ Anaç ortalama } \\
\hline & Kabarcık & Hönüsü (Mahrabaşı) & \\
\hline 1103 Poulsen & $85.66^{a}$ & $75.33^{\mathrm{ab}}$ & $80.50 \mathrm{~A}$ \\
\hline $110-R$ & $66.00^{b}$ & $49.00^{c}$ & $57.50 \mathrm{~B}$ \\
\hline Çeşit ort. & $75.83 \mathrm{~A}$ & $62.16 \mathrm{~B}$ & \\
\hline D Anaç: $11.32^{* *}$ & & $\mathrm{t}: 11.23^{*}$ & D Anaç x Çeşit : 16.04 \\
\hline
\end{tabular}

(1): Ortalamalar arasındaki farklar farklı harflendirilmeyle belirtilmiştir.

(2): Ö.D.: Önemli Değil, **:p<0.01; * $: p<0.05$

Çizelge 10. Değişik anaçların kabarcık ve hönüsü (mahrabaşı) üzüm çeşitlerinin fidan randımanı (\%).

\begin{tabular}{|c|c|c|c|}
\hline \multirow[t]{2}{*}{ Anaçlar } & \multicolumn{2}{|c|}{ Çeşitler } & \multirow[t]{2}{*}{ Anaç ortalama } \\
\hline & Kabarcık & Hönüsü (Mahrabaşı) & \\
\hline 1103 Poulsen & $60.66^{a}$ & $42.00^{b}$ & $51.16 \mathrm{~A}$ \\
\hline $110-\mathrm{R}$ & $37.00^{b}$ & $41.67^{b}$ & $39.50 \mathrm{~B}$ \\
\hline Çeşit ort. & $48.83 A$ & 41.83B & \\
\hline D Anaç $: 6.38^{* *}$ & & it : $6.44^{*}$ & D Anaç x Çeşit : $9.11^{* *}$ \\
\hline
\end{tabular}

(1): Ortalamalar arasındaki farklar farklı harflendirilmeyle belirtilmiştir.

(2): Ö.D.: Önemli Değil, **:p<0.01; * : $<<0.05$

\section{Sonuç ve Öneriler}

Modern bağ tesisinde doğru anaç ve çeşit kullanımı, oluşturulacak yeni bahçelerin en önemli unsurlarından biridir. Bu yüzden yeni kurulacak bağ kapama bahçelerinin uzun ömürlü ve ekonomik olabilmesi buna bağlıdır. Yeni kurulacak olan bağlarda anaç ve çeşit seçimi ne kadar uygun olursa başarı oranı da yüksek olacaktır. Bu amaçla anaç ve çeşit seçimi bölgenin iklim ve toprak yapıları dikkate alınarak yapılması gerekmektedir.

Kahramanmaraş ilinde bağcılık yaygın olarak yapılmaktadır. Özellikle Kabarcık ve Hönüsü çeşitleri bölgeye uyum sağlamış ve özdeşlemiş üzüm çeşitlerinin en önemlileridir. Son yıllarda hastalıklı ve eski bağ alanlarının yenilenmesi ve bölgeye iyi adapte olmuş yeni çeşitlerin dikilmesi amacıyla yeni bağlar tesis edilmektedir. Yeni kurulacak olan bağlarda dikkate alınacak en önemli hususlardan birisi günümüzde anaç kullanımıdır. Ancak Kahramanmaraş bölgesinde bahçelerin çoğunda yaşı (eski) anaçlar üzerine aşı uygulaması yapılarak yetiştiricilik yapılmaktadır. Amerikan anaçlarının köklenme kabiliyetleri incelendiğinde, farklı çeşitler üzerine farklı özellikler gösterdiği ve köklenmesi zor olan çeşitlerin fidan üretiminde kullanılmasının bağ yetiştiriciliğinde olumsuz etki gösterdiği bilinmektedir.

Sonuçta, araştırmanın yürütüldüğü yöre şartlarında yaygınlaştırılmaya çalışılan üzüm çeşitlerinin fidan kaliteleri bakımından en iyi özellikleri 1103 Poulsen anacı üzerine asılı kombinasyonlarda tespit edilmiştir. Bölgede bağ yetiştiriciliği yapan üreticilere önerilmektedir. Diğer yönden 110-R anacının ise düşük performans göstermesi dikkate değer bulunmuş olup yöre bağcılığını önerilmemektedir. Bölge yetiştiriciliği bakımından önemli çeşitler olan Kabarcık ve Hönüsü üzüm çeşitlerinin farklı anaçlarla ilişkilerinin ortaya konulması amacıyla farklı bölgelerde çeşit/anaç adaptasyon denemelerin yapılması gerekmektedir. Araştırma sonucunda elde edilen bulgulara göre, tüplü asma fidanı üretiminde başarı sağlanabilmesi için çeşitlerin farklı anaç kombinasyonlarına göre farklılıklar ortaya çıkardığı görülmektedir. Bu nedende bölgede yoğun yetiştiriciliği yapılan çeşitlerle sertifikalı ve ismine doğru fidanlarda bahçe tesis edilmesi elzemdir. Benzer çalışmalar yapılarak, farklı anaçlarında Kabarcık ve Hönüsü üzüm çeşitlerinde denenmesinin faydalı olacağı gözükmektedir.

\section{Kaynaklar}

Ağaoğlu, Y., Çelik, H. 1978. Bazı Amerikan asma anaçlarında ethrel uygulamaları ve dikim şekillerinin köklenme üzerine etkileri. Ankara Üniversitesi Ziraat Fakültesi Yıllığı, Cilt: 27, Fasikül I'den Ayrı Basım.

Akman, i., Ilgın, C. 1991. Tüplü asma fidanı üretiminde başarıyı etkileyen faktörler. T.C. Tarım ve Köy İşleri Bakanlığı Türkiye I. Fidancilık Sempozyumu, Ankara.

Anonim, 2017. Kamu/Özel Sektör Fidan Üretimleri 2004, 2005, 2006. Tarım ve Köy isleri Bakanlığı. Bitkisel Üretim Birimi. http://fidan.gov.tr (14.07.2009).

Altındisli, A., Kara, S., Kısmalı, D. 1998. Tüpte ve kasada farklı ortamların fidan randımanı ve kalitesine etkileri. 4. Bağcılık Semp., Yalova, s.217-221.

Arslan, S. 2015. Ürün Raporu. Tarımsal Ekonomi ve Politika Geliştirme Enstitüsü.. TEPGE Yayın No: 268. ISBN:978-605-9175-41-8. 
Cangi, R. 1998. Asma fidanı gelişimine anaçların etkileri üzerine bir araştırma. 4. Bağcılık Semp. Yalova. s.412-416.

Cangi, R., Kelen, M., Doğan, A. 1999. Serin iklim koşullarında asma fidanı üretim olanakları. Türkiye III. Ulusal Bahçe Bitkileri Kongresi, Eylül 1999, Ankara, s.430-435.

Çakır, A., Karaca, N., Sidfar, M., Baral, Ç., Söylemezoğlu, G. 2013. Sultani çekirdeksiz üzüm çeşidinin farklı Amerikan asma anaçları ile aşı tutma oranlarının belirlenmesi. YYÜ. TAR. BIL. DERG. 23(3): 229-235.

Çelik, H., Ağaoğlu, Y.S. 1979. Aşılı köklü asma fidanı üretiminde farklı çeşit/anaç kombinasyonlarının aşıda başarı üzerine etkileri. Ank. Üniv. Zir. Fak. Yıllığı 79(1): 222232.

Çelik, H. 1982. Kalecik Karası/ 41 B Aşı Kombinasyonu İçin Ser Koşullarında Yapılan Aşılı Köklü Fidan Üretiminde Değişik Köklenme Ortamları ve NAA Uygulamalarının Etkileri. Ank. Üniv. Zir. Fak. (Basılmamış Doçentlik Tezi), 73s.

Çelik, H. 1985. Asılı koklu asma fidanı üretiminde başarıyı etkileyen etmenler. Türkiye I. Bağcılık Semp., Cilt I., Tekirdağ, s.139-153.

Çelik, H., Akgül, V. 1992. Aşılı Asma fidanı üretiminde değişik katlama yöntemlerinin aşıda başarı üzerine etkileri. Türkiye I. Ulusal Bahçe Bitkileri Kongresi, 13-16 Ekim, Cilt 2: 455-458. İzmir.

Çelik, H., Odabaşı, F. 1994. Bağcılıkta uyuşma ve afinite. Hasat Dergisi (Ocak): 37-41.

Çelik, H., Odabaşı, F. 1995. Farklı anaçlar üzerine aşılanan bazı uzum üzerinde ası tipi ve asılama zamanlarının fidanların büyüme ve gelişmeleri üzerine etkileri. Türkiye II. Bahçe Bit. Kong. Cilt II. Adana. s.464-468.

Çelik, H., Ağaoğlu, Y.S. Fidan, Y., Marasalı, B., Söylemezoğlu, G. 1998. Genel Bağcllık. Sunfidan A.Ş. Mesleki Kitaplar Serisi:1, Fersa Matbaacılık, Kızılay-Ankara.

Çelik, H., Kunter, B., Söylemezoğlu., G., Ergül, A., Çelik, H., Karataş, H., Özdemir, G., Atak, A. 2010. Bağcılığın Geliştirilmesi Yöntemleri ve Üretim Hedefleri. Türkiye Ziraat Mühendisliği VII. Teknik Kongresi Bildiri Kitabı, Cilt 1: 493513, Ankara.

Çoban, H., Kara, S. 2003. Bazı üzüm (Vitis vinifera L.) çeşitlerinin asma anaçları ile aşı tutma durumu ve fidan kalitesine etkileri üzerine araştırmalar. Anadolu Ege Tarımsal Araştırmalar Enstitüsü Dergisi, 13(1): 176-187.

Eriş, A., Soylu, A., Türkben, C. 1989. Aşılı köklü asma fidanı üretiminde bazı uygulamaların aşı yerinde kallus oluşumu ve köklenme üzerine etkileri. Bahçe, 18 (1-2): 29-34.
Ecevit, F., Baydar, N. 2000. Asılı asma Fidanı Üretiminde Farklı Asılama Yöntemlerinin Asıda Başarı Üzerine Etkileri. II. Ulusal Fidancılık Semp. Ödemis.

Göktaş, A. 2008. Üzüm Yetiştiriciliği. Eğirdir Bahçe Kültürleri Araştırma Enstitüsü Müd. Yayın No:18. Yayın Tarihi: 01.01.2008.

Hartman, H.T., Kester, D.E. 1974. Bahçe Bitkileri Yetiştirme Tekniği (Çevirenler; Kaşka, N. ve Yılmaz, H.,). Çukurova Üniversitesi Ziraat Fakültesi Yayınları: 79. Ders Kitapları: 2. $601 \mathrm{~s}$.

Kamiloğlu, Ö., Tangolar, S. 1995. Aşılı asma fidanı üretiminin geliştirilmesi üzerinde bir araştırma. Türkiye II. Ulusal Bahçe Bitkileri Kongresi, Adana. Cilt II, s.447-451.

Laszlo, I., Valeanu, L. 1969. The storage of vine propagating material under controlled temperature conditions. Rev. Hort. Vitis. 18(19): 40-50.

Söylemezoğlu, G., Kunter, B., Akkurt, M., Sağlam, M., Ünal, A., Buzrul, S., Tahmaz, H. 2015 Bağcılığın Geliştirilmesi Yöntemleri ve Üretim Hedefleri. Türkiye Ziraat Mühendisliği VIII. Teknik Kongresi, s.606-630.

Sivritepe, N., Türkben, C. 2001. Müşküle Üzüm çeşidinde farklı anaçların aşıda başarı ve fidan randımanı üzerine etkileri. Uludağ Üniv. Zir. Fak. Derg., 15(2001): 47-58.

Sucu, S., Yağcı, A. 2017. Bazı asma anaçları ve bu anaçlar üzerine aşılı sultani çekirdeksiz çeşidinde fidan randımanı ve kalite özelliklerinin belirlenmesi. Ege Üniv. Ziraat Fak. Derg., 2017, 54(1): 53-59 ISSN 10188851.

Tangolar, S., Ergenoğlu, F. 1989. Değişik anaçların erkenci bazı uzum çeşitlerinde vegetatif gelişimi üzerine etkileri. Doğa, 13(3B): 12421266.

Tuncel, R., Dardeniz, A. 2013. Aşılı asma çeliklerinin fidanlıktaki vejetatif gelişimi ve randımanları üzerine katlamanın etkileri. Tarım Bilimleri Araştırma Dergisi 6(1): 118-122, 2013.ISSN: 1308-3945, E-ISSN: 1308-027X.

Türkben, C., Sivritepe, N. 2000. Asılı koklu asma fidanı üretiminde bazı dışsal uygulamaların ası yerinde kallus oluşumu ve kökleşme üzerine etkileri. II. Ulusal Fidancılık Semp. Ödemiş. s.29.

TÜik, 2017. Türkiye İstatistik Kurumu. http://www.tuik.gov.tr/(Erişim tarihi:08.11.2017). 